at the level needed to convert a marginal diet into an optimal diet.

The commonly accepted view that the equation

$$
\underset{\beta \text {-carotene }}{\mathrm{C}_{40} \mathrm{H}_{58}} \stackrel{2 \mathrm{H}_{2} \mathrm{O}}{\rightarrow} \quad 2 \mathrm{C}_{20} \mathrm{H}_{29} \mathrm{OH}
$$

corresponds with a process occurring in vivo would lead to $1.56 \times 10^{6} \mathrm{I} . \mathrm{U} . / \mathrm{gm}$. for pure vitamin $\mathrm{A}$. This is not in aecord with experience; it rests upon the assumption that fission occurs exclusively at $\mathrm{Cl} 5-15^{\prime}$ double bond, and its only advantage is that it agrees with the superiority of $\beta$-carotene over other provitamins. Unsymmetrical fission is more plausible and an equation

$$
\mathrm{C}_{40} \mathrm{H}_{56} \rightarrow \mathrm{C}_{20} \mathrm{H}_{29} \mathrm{OH}+\text { decomposition products }
$$
$\beta$-carotene

is in closer harmony with the observed potency of vitamin A.

Vitamin A is estimated spectroscopically by utilizing the absorption maximum at $325 \mathrm{~m} \mu$. There is at present no reason to justify changing the accepted conversion factor, namely :

$$
\mathrm{E}_{1 \mathrm{~cm} .}^{1 \%}{ }_{325 \mathrm{~m} \mu, \mathrm{l}=1,600 \text { I.U./gm. }}^{1 \%}
$$

The estimation of carotene in dried grass and similar materials involves extraction of the pigments, preparation of non-saponifiable extracts and a phase separation (that is, partition between petrol ether and 90 per cent methyl alcohol). The provitamins appear in the hydrocarbon' solvent and the xanthophyllic compounds are eliminated in the aqueous methyl alcohol. Chromatographic adsorption permits a finer separation of individual carotenoids, specially prepared alumina, lime, calcium carbonate, magnesia and soda ash being good absorbents for particular purposes. The carotene, freed from 'xanthophylls', is evaluated spectroscopically or colorimetrically.

Dried grass and similar products are now important sources of provitamin A for animal feeding. The following method of analysis has been thoroughly tested and found to be satisfactory by the Grass Driers' Association :

$0.25 \mathrm{gm}$. dried grass is ground thoroughly with sharp silver sand $(5 \mathrm{gm}$.) and the mixture is treated with a mixture of acetone $(15 \mathrm{ml}$.) and petrol ether $(45 \mathrm{ml}$.) in a continuous drip extractor for at least 1 hour. The cooled extract is transferred to a separating funnel using a little petrol for washing in, and 30 per cent methyl alcoholic potash $(5 \mathrm{ml}$.) is added. Vigorous shaking for two to five minutes is followed by addition of water $(200 \mathrm{ml}$.). Carotene remains in the petrol, and after washing with water $(200 \mathrm{ml}$.) the 'xanthophylls' are removed by shaking the petrol ether three times with 90 per cent methyl alcohol. The petrol layer is retained and made up to known volume. A solution of potassium dichromate $(0.025$ per cent) is colorimetrically equivalent to a solution of $\beta$-carotene containing $0.158 \mathrm{mgm}$. per $100 \mathrm{ml}$. petrol ether.

The estimation of carotene is complicated by the presence in the petrol ether fraction of a variable amount of an $X$-substance, which may be eliminated by filtering through a short column of alumina after adding 3 per cent of acetone. A yellow impurity is adsorbed but the carotene is carried through. Dr. Kon has confirmed the observation that the percentage of this contaminant increases in dried grass on storage.

\title{
THE AMERICAN ASSOCIATION FOR THE ADVANCEMENT OF SCIENCE Columbus MeEting
}

\section{By Dr. F. R. Moulton, Permanent Secretary of the American Association}

IN many respects the American Association for the Advancement of Science is similar to the British Association, which served as a model for its organization and early development. It is the great democratic scientific organization of America (using the word in the geographical, not the national, sense), including in its interests all of science and its applications and relations to society. During a period of rapid increase in specialization and the organization of special scientific. societies, it has served as an integrating agency. The breadth of its scope and the number $\mathrm{cf}$ its members, now exceeding 20,000 , make its voice more and more the voice of science in America.

In certain respects, however, the American
Association differs from the British Association. Perhaps the least important is that it holds two meetings each year, the annual meeting during the Christmas holiday week (this year December 27January 2, inclusive) and another meeting in the summer, usually the latter part of June. In addition, because of the large area of America, it has two geographical divisions, the Pacific Division and the Southwestern Division, each of which holds one meeting each year. A greater difference between the two associations is in the nature of their programmes. Before stating this difference, I wish to point out that many special scientific societies and organizations, at present 174 of them, are affiliated with the American Association, meet 
with it at their option, and have representation on its Council, its supreme governing body. As a consequence of this organization, the American Association programmes, instead of consisting of a rather small number of important addresses by distinguished men of science, include many sessions before which hundreds of papers are read. At the recent meeting in Columbus, Ohio, in about four days a total of 259 scientific sessions were held, before which 2,154 addresses and papers were presented. Naturally there was none of the delightful leisureliness of the meetings of the British Association.

Although many, probably most of the 2,154 papers presented at the Columbus meeting were of no considerable importance, yet a considerable number were distinguished. As an example, I may refer to the paper by I. I. Rabi on "Radio Frequency Spectra of Atoms and Molecules", for which the Thousand Dollar Prize of the Association was awarded. Dr. Rabi not only discovered radiations from atoms of much lower frequency than hitherto known, but also devised a method of determining their properties although they are far too feeble to be detected by any of the devices previously in use. It is not possible to pick out from the hundreds of other papers - 75 in physics, 44 in chemistry, 56 in astronomy, more than 300 in the zoological sciences, more than 350 in the botanical sciences, an equal number in genetics and other general biological sciences, 67 in the medical sciences, 310 in agricultural science-a few for special comment without injustice to many others.

On the whole, the best part of the programme from the point of view of direct contributions to science was the symposia, often organized and presented by several sections and societies in co-operation. These symposia were on such subjects as "Applications of Mathematics to the Earth Sciences", "Photosynthesis", "Fifty Years of Entomological Progress", "Speciation", "Effects of Science upon Human Beings" and "Blood, Heart and Circulation". The Association has published in book form the most important of the symposia presented at its meetings during the past three years.

Perhaps the foregoing paragraphs might lead the reader to conclude that the programmes of the American Association do not include the general sessions which are so characteristic of meetings of the British Association. The American Association has such general sessions, often of distinction, but relatively to the remainder of its programme they are much less important than those of the British Association. In addition to the address of the retiring president of the Association, there are two regular evening general sessions, one under the auspices of the Society of the Sigma Xi, an honorary scientific society, and one under the auspices of the Phi Beta Kappa, an honorary scholarship society. The retiring president of the Association, Dr. Wesley C. Mitchell, chose for the subject of his address "The Public Relations of Science" [see Nature, Feb. 10, p. 207]. The annual lecture under the auspices of the Society of the Sigma Xi was delivered by Dr. Kirtley F. Mather on "The Future of Man as an Inhabitant of the Earth". The Phi Beta Kappa address was by Dean Marjorie Hope Nicolson on "Science and Literature".

This year saw the initiation of two new general sessions, one under the auspices of the Honor Society of Phi Kappa Phi and the other under the arrangement between the British Association and the American Association for exchange lectures on alternate years. The former was delivered by Dr. Isaiah Bowman, president of the Johns Hopkins University, whose subject was "Who is Responsible for Peace ?" As British men of science will recall, Dr. Bowman was invited by the officers of the British Association to deliver at its meeting last September the first of the British and American Association Lectures.

Although the first lecture by a British man of science under the arrangement was not due until next June, the arrival of Dr. Julian S. Huxley in America just before the Columbus meeting presented an opportunity that could not be neglected. He was invited to deliver the first lecture by a British scientific worker and accepted the invitation. His subject was "Science, War and Reconstruction". In referring to this brilliant address in my report of the meeting, I wrote as follows :

"The address of Dr. Huxley illustrated the scientific ideals of impartiality, justice and altruism, not simply as ideals without immediate applications but as ideals that are urgently needed at this hour. Obviously there is now a tide in the affairs of scientists that taken at its flood may enable them to make the greatest contribution to the progress of mankind in the history of the world, but neglected may leave them in the position of having provided the bark on which civilization will drift back into the darkness from whence it came. It is gratifying that so many addresses and programs of the association and its affiliated societies gave concrete evidence of a deep feeling of responsibility of scientists to society. These responsibilities include also the more fundamental one of laying foundations for an organization of society based. on the essential nature of man ; and they include the still deeper one of deriving from the laws of the inanimate and animate universes about us and within us a basis for ethics whose authority for acceptance shall be in our own hearts." 